\title{
LA HIPÓSTASIS DEL PROSUMO, O LA EXPLOTACIÓN DEL TRABAJO DE CONSUMO*
}

\section{THE HYPOSTASIS OF PROSUMPTION, OR THE EXPLOITATION OF CONSUMER LABOR}

\author{
Xavi Cava Gómez ${ }^{1}$ \\ xavicava@gmail.com \\ Universidad de Barcelona \\ Barcelona, España \\ DOI: https://doi.org/10.32735/S2735-61752019000116140
}

\section{RESUMEN}

El debate en torno a lo que algunos teóricos denominan prosumo nos proporciona una línea argumental para discutir ciertos elementos distintivos del consumo a principios del siglo XXI. Empezaré por considerar el origen del concepto y el significado que se le ha dado como una actividad que combina producción y consumo. A continuación profundizaré en tres elementos centrales del debate: la posibilidad de que el prosumo esté preparando el terreno para el desarrollo de una supuesta nueva economía, la teoría de que el consumo incorpora elementos propios de la producción, y la hipotética capacidad del prosumo para empoderar a los prosumidores. Para acabar, argumentaré que el concepto de prosumo no es más que una hipóstasis sin referente material, y que la apología de esta teoría tiende a ignorar que se trata de una forma de explotación.

Palabras claves: prosumo, nueva economía, trabajo no remunerado, valor, explotación.

\begin{abstract}
The discussion about what some scholars name as prosumption offers us a guiding thread to consider some distinctive features of consumption in the early twenty-first century. I will take into account the origin of the concept of prosumption and its meaning, namely an activity that combines both production and consumption. Then I will ponder three key elements in the discussion: the possibility that prosumption could lead the way to a so-called new economy, the theory that consumption can incorporate elements of production, and the alleged ability of prosumption to empower prosumers. Finally, I will argue that the concept of prosumption is just a hypostasis that refers to no actual content. Actually is a word used to conceal a form of exploitation.
\end{abstract}

Key words: prosumption, new economy, unpaid work, exchange, exploitation.

\footnotetext{
* Artículo recibido el 21 de diciembre de 2017; aceptado el 31 de enero de 2018.

1 El autor es parte del programa de doctorado de Ciudadanía y Derechos Humanos por la Universitat de Brcelona y vinculado al grupo de investigación de Norbert Bilbeny (el antiguo grupo de Bermudo), formando parte de su proyecto de investigación "Nuevas formas de acción política en la era de la comunicación".
} 


\section{Origen y significado del concepto de prosumo}

El concepto o hipótesis del prosumo y su figura asociada, el prosumidor, circulan por diferentes ámbitos académicos desde hace relativamente pocos años. Hacen referencia a una tendencia que, a juicio de sus defensores, es cada vez más intensa en las sociedades contemporáneas: la progresiva erosión de la distinción entre la actividad de producción y la actividad de consumo en el seno de la esfera del propio consumo. Su uso, sin embargo, no parece haber traspasado la frontera de la academia para circular entre el público en general, al menos hasta el momento. Vamos a empezar, entonces, por establecer una breve genealogía del concepto, para a continuación discutir su sentido y el debate que se ha abierto a su alrededor.

Se suele atribuir la acuñación del término prosumidor al futurólogo Alvin Toffler; ${ }^{2}$ si bien no fue su auténtico creador, si que se le puede considerar como el autor lo difundió entre un público relativamente amplio en la década de los 80 . Toffler lo empleó en su conocido best-seller $L a$ tercera ola para referirse a un nuevo sujeto socio-económico que, a su juicio, estaba destinado a protagonizar la economía del futuro. En la figura del prosumidor se estarían sintetizando los rasgos que definen al productor y los del consumidor como consecuencia de una tendencia que, en un futuro no muy lejano según Toffler, se materializaría en una nueva estructura económica que trascendería el capitalismo clásico (Toffler, 1980).

Toffler analizó los cambios en la forma de consumir de las sociedades occidentales que se sucedieron a partir de la década de los 70 y que, a su juicio, iban a afectar profundamente la misma organización de la producción capitalista. Los cambios que conformaban el que iba a ser el nuevo modelo de consumo pueden parecer hoy evidentes, pero en su momento fueron saludados por algunos como una promesa de libertad o, en una expresión más contemporánea, de empoderamiento. Según esto, se creía que aquellos consumidores de los 70 y los 80 empezaban a tomar conciencia de su fuerza y capacidad de decisión, de manera que sus decisiones de compra ya no eran pasivas ni se limitaban a adaptarse a una oferta predeterminada. Por el contrario, adoptaban una actitud cada vez más exigente y, en cierta forma, 'participativa', que tendía a influir en la oferta de consumo. Para Toffler, a largo plazo esto iba a tener un efecto radical sobre la misma organización económica capitalista. En su opinión y la de muchos otros, esta transformación empezaba a ser perceptible en muchos ámbitos de la sociedad de los 80 . Así, por ejemplo, las empresas de marketing tomaban cada vez más en consideración los deseos, opiniones y gustos de los consumidores a la hora de diseñar estrategias de producción y comercialización de las mercancías, de manera que la influencia en las decisiones de producción se trasladaba de los despachos de gerencia a los de publicidad y marketing (Tsogas, 2013). El establecimiento de vínculos emocionales entre el consumidor y el objeto de consumo, materializado en la identificación con la marca comercial, se defendía como el ejemplo paradigmático del cambio en los valores de consumo, según el cual los criterios racionales (utilidad, relación coste-calidad) eran sustituidos o complementados por nuevos criterios subjetivos (emocionales, estéticos, identitarios, éticos...).

Esta aparente 'revolución' en las pautas de consumo debía tener unas causas. Para Toffler, las razones de fondo que explicaban tales cambios de hábito eran de tipo cultural y político. Su argumento era que, desde finales de los años 60 , se habían estado experimentando

2 La profesión de futurólogo, contra lo que pudiese pensarse en un primer momento, parece gozar de gran prestigio a juzgar por la lista de personalidades en las que ha influido Toffler, en la que se incluyen políticos como Mijaíl Gorbachov, Newt Gingrich o Zhao Ziyang, y empresarios como Carlos Slim o Ted Turner. 
importantes transformaciones en las sociedades occidentales en dirección a una mayor libertad individual, una mayor tolerancia social, un creciente respeto e incluso culto a la diferencia, y una nueva cultura del desarrollo personal. Transformaciones que en gran medida se inspiraban en la contra-cultura de los Estados Unidos, un movimiento inicialmente alternativo y contestatario cuyos valores terminaron por ser asimilados por buena parte de las sociedades occidentales. La imagen de un consumidor 'emancipado' era solo una de las caras en las que se manifestaba un creciente empuje en pro de la libertad y el crecimiento personal: en definitiva, se trataría de la emergencia de una subjetividad que, encorsetada por la disciplina y la moralidad dominantes, pugnaba por eclosionar. Con estos argumentos Toffler no hacía más que abundar en la tesis que asocia el liberalismo económico con el liberalismo político. Su particularidad era que proyectaba hacia el futuro, magnificándolo, el discurso de que el capitalismo es el sistema que establece el terreno más fecundo para la libertad individual. Su hipótesis era que las sociedades capitalistas estaban entrando en una nueva era en la que los individuos irían adquiriendo paulatinamente mayor control no solo sobre qué y cómo consumir, sino también sobre la misma producción. Al final de ese proceso de transformación, la economía supuestamente dejaría de estar gobernada por una pequeña élite de gestores y propietarios, y se gestionaría en función de los deseos y necesidades de una gran masa de prosumidores. Estos se constituirían, en ese esquema, en la figura dominante de una nueva organización de la economía y la sociedad. El sueño de una sociedad de propietarios transformado en el sueño de una sociedad de consumidores.

La prueba del tiempo ha dejado la predicción de Toffler en la cuneta de la historia. A estas alturas es irrelevante preguntarse si su error fue fruto de la buena intención o un ejercicio de cinismo. Ante el renacimiento que ha experimentado el concepto de prosumo en los últimos años, lo realmente importante es acotar los puntos débiles de su discurso y determinar si se están repitiendo en nuestro contexto. Hay que señalar ante todo que su argumento se apoyaba en un presupuesto de base: la primacía de lo cultural sobre lo económico. A su juicio, iban a ser los cambios en el sistema dominante de valores y creencias los que provocarían una transformación de la economía capitalista en un sentido progresista. Ahora bien, si invertimos ese argumento y tomamos como punto de partida del razonamiento la crisis que padeció el capitalismo tras el crecimiento posterior a la Segunda Guerra Mundial, a nuestro juicio podemos desarrollar un análisis más preciso y claro. Es en las causas de la crisis y en la reacción subsiguiente donde podemos hallar algunas de las causas que explican muchas de las transformaciones sociales. Desde mediados de los 60 se estaban extendiendo fenómenos como la automatización de las fábricas, la generalización de procesos de deslocalización, o la implementación de nuevas técnicas de producción basadas en principios organizativos como el just-in-time o el toyotismo. Una reestructuración del sistema productivo capitalista (esta, a diferencia de la imaginada por Toffler, bien real) a escala global. Todos estos avances en la productividad implicaban que las mercancías salían de las factorías en cantidades cada vez mayores, con la amenaza consiguiente de una crisis de sobreproducción. Consecuentemente, era necesario desarrollar nuevos incentivos para que el consumo estuviese a la altura de la inmensa cantidad de bienes que inundaban los mercados. En definitiva, había que crear una demanda para toda aquella oferta.

Una de las diversas respuestas que se ensayaron para responder a ese desafío fue producir mercancías cada vez más diferenciadas o personalizadas. Los avances tecnológicos asociados a la automatización y la robotización, basdos en la gestión informática, permitían producir de forma cada vez más acelerada y eficiente mercancías que, sin perder una homogeneidad de base, incorporaban rasgos que las particularizaban. La diferenciación entre mercancías 
incentivaba en los consumidores la afición a elegir entre diferentes variantes de un mismo producto, de manera que se activaba un proceso de retroalimentación: a mayor variedad en la oferta, mayor especialización y refinamiento del consumidor en sus hábitos de consumo. Otra respuesta a la necesidad de incentivar el consumo, como ya hemos mencionado, fue la consolidación de la marca comercial como un dispositivo diseñado para lograr la identificación subjetiva, la implicación emocional del consumidor con las mercancías que iba a consumir. Es cierto que los diferentes procedimientos para activar esta identificación (ligar la marca a valores o sentimientos, asociarla a un determinado estándar de calidad, etc) no eran exactamente nuevos: lo novedoso fue la generalización del proceso y las consecuencias sociales que arrastró consigo. Un cambio cuantitativo se tradujo en un cambio cualitativo, o cuanto menos contribuyó a ello. De esta forma, la personalización de las marcas comerciales puede interpretarse como uno de los elementos que, desde el consumo, contribuyó a la expansión de la subjetividad que mencionábamos antes.

Puede argüirse así que la serie de transformaciones en el sistema productivo capitalista influyó tanto sobre los cambios sociales en las últimas décadas del siglo XX, como sucedió a la inversa. En cualquier caso, aunque la industria empezó a tener más en cuenta las opiniones y necesidades de los consumidores (bien fuese para adaptarse a ellas, bien para moldearlas según sus necesidades), esto no tuvo como consecuencia ningún cambio en la estructura económica en el sentido específico que planteaba Toffler. Todo lo contrario, mantuvo e incluso intensificó su carácter capitalista. La predicción del advenimiento de una nueva era en la que se harían realidad la superación del capitalismo y la democratización de la economía se acabó revelando ingenuamente optimista.

Con el reflujo de la oleada conservadora de los 80 y principios de los 90 la figura del prosumidor desapareció del debate, y no abandonó la lista de teorías fallidas hasta unos años después, cuando el desarrollo de internet sentó las condiciones materiales que empujarían a la necesidad de volver a plantear la hipótesis del prosumo. El primer aviso de que algo se volvía a mover en torno a esta cuestión fue la popularización, en cierta literatura académica, del concepto de cocreación de valor (Prahalad y Ramaswamy, 2000; Ramirez, 1999; Zwick, Bonsu y Darmody, 2008). Mediante este concepto se pretendía poner en valor la utilidad que para muchas empresas podría suponer el cooptar y aprovechar las iniciativas, sugerencias y motivaciones de los consumidores de sus productos. En otras palabras, se trataba de incentivar la participación del consumidor en la creación de valor. Ahora bien, en la medida en la que esta teoría se planteaba desde posiciones muy alejadas de la teoría marxista, y por tanto no tenía en cuenta la distinción entre valor y valor de uso, el contenido del concepto era muy vago. La teoría de la cocreación de valor se sigue trabajando hoy en día, particularmente en el campo de la gestión empresarial y el márketing, y en la medida en que aborda cuestiones ligadas al trabajo en la fase de consumo, tiene un cierto interés en nuestro contexto. Sin embargo, en nuestra perspectiva es mucho más importante la reaparición del concepto de prosumo pocos años después, especialmente a partir de la publicación, en 2010, del artículo seminal de George Ritzer Production, Consumption, Prosumption. The nature of capitalism in the age of the 'digital' prosumer (Ritzer, 2010).

Como decíamos, esta 'segunda vida' del prosumo está estrechamente ligada a la expansión de la tecnología digital. Internet, la conectividad en red y, muy particularmente, lo que a partir del 2006 se empieza a denominar "web 2.0" introducen en el tejido capitalista una nueva forma de producir, distribuir y consumir productos fundamentalmente digitales. Las tecnologías y aplicaciones desarrolladas en los últimos 10 o 15 años permiten a los usuarios superar el mero consumo pasivo de contenidos digitales para pasar a tener la capacidad de modificarlos, 
colaborar en su producción e incluso crear y compartir los suyos propios. Más aún (y aquí es donde entra en juego la idea del prosumo) tal y como está configurada la actual esfera digital, en la que la 'navegación' por internet deja de ser un proceso pasivo y contemplativo para pasar a ser activo y participativo, con frecuencia es imposible separar de forma clara lo que es consumo de lo que es producción. Para ejemplificar esta paradoja, tomemos el caso de un usuario de Facebook. Cuando este usuario cuelga una imagen en su perfil, ¿está simplemente consumiendo los servicios que ofrece la plataforma, o está al mismo tiempo produciendo su perfil en ella? ¿Dónde empieza y dónde acaba cada una de estas actividades? Y respecto a la propia empresa, ¿la actividad de ese usuario es un consumo meramente pasivo de los servicios, o más bien le está aportando una información vital, un trabajo que constituye la materia prima para que posteriormente la venda a las empresas anunciantes?

Estas y muchas otras cuestiones han despertado el interés desde diferentes disciplinas por la tecnología 2.0 y los usos y consumos que hace posible (Bruns, 2008; Burrows \& Beer, 2010; Zwick, Bonsu \& Darmody, 2008). Un poco en la ola de Toffler, desde algunas posiciones se está planteando otra vez la tesis de que la economía está entrando en una nueva era de transformación radical. Se postula el nacimiento de una 'nueva economía' en la que el principio de la colaboración en red sustituirá al de la competencia, y cuya base será la abundancia de recursos (digitales) en lugar de su escasez. Ahora bien, los defensores de esta tesis ignoran o pretenden ignorar que, a estas alturas, internet está ya gobernada por la mercantilización y la lógica capitalista, en un proceso de subsunción que no tiene visos de ser reversible. Así las cosas, cabe sospechar que la 'nueva economía' no es mas que el (nuevo) rostro amable mediante el que se avala desde el ámbito teórico el capitalismo de principios del siglo XXI. Un capitalismo que estaría ampliando sus mecanismos de extracción de riqueza a medida que coloniza el universo digital, pero también más allá, extendiéndolos al conjunto de la esfera de consumo.

Por ello, en torno a la cuestión del prosumo se teje un conjunto de discusiones de gran interés para la crítica de la economía política. Si vale la pena atender a los discursos apologéticos sobre el prosumo, así como a la literatura crítica que ha aparecido al mismo tiempo (Comor, 2010; Fuchs, 2014; Terranova, 2000) es porque en ese debate entran en juego conceptos como trabajo, explotación y consumo tal como aparecen en el contexto del capitalismo contemporáneo. $Y$ esto conduce a plantear hasta qué punto es necesaria 0 no su reconsideración y reformulación. Es por ello que, a continuación, vamos a repasar brevemente los principales temas que se exponen en torno al prosumo y los argumentos que los acompañan.

\section{Ámbitos de discusión en torno al prosumo}

Las voces que podríamos calificar de 'apologéticas' del prosumo centran su discurso, como ya hemos señalado, en el desarrollo de la esfera digital como espacio propicio en el que, esta vez sí, la figura del prosumidor pueda materializarse. Coinciden en defender que las tecnologías asociadas a la web 2.0 contienen, al menos potencialmente, la posibilidad de 'empoderar' a los usuarios de internet. La medida de este empoderamiento la dará la capacidad de esos usuarios para actuar efectivamente como prosumidores. Esta posibilidad se apoya básicamente en tres cuestiones. Primero, en el hecho de que estas tecnologías facilitan un alto grado de participación activa, lo que permite a sus usuarios participar de la producción de los contenidos que son consumidos en internet, ya sea porque actúan como simples re-productores de esos contenidos (contribuyendo a su difusión), porque los alteran y recombinan de acuerdo a sus 
gustos e intereses, o porque directamente los producen. En segundo lugar, el funcionamiento de la tecnología de la web 2.0 se fundamenta en gran medida en la colaboración entre los usuarios, lo que fomenta la interacción y el desarrollo de una estructura de creación en red que estaría, supuestamente, sentando las bases para una nueva forma de producción. En tercer lugar, la circulación de ingentes masas de información, prácticamente imposibles de gestionar en su conjunto, implica que la cuestión ya no está en competir por conseguir y aprovechar de la forma más eficiente unos recursos escasos, sino en saber gestionar esa abundancia que tiende a desbordar las capacidades de los usuarios y de la misma red. Esto apuntaría hacia la necesidad, en un futuro cercano, de organizar un nuevo modelo económico basado en principios como colaborar y compartir, frente al modelo clásico basado en competir y poseer.

No hay duda que los rasgos apuntados hasta aquí son familiares para la mayoría de los internautas que se relacionan con la web 2.0. Ahora bien, el paso teórico que se da al interpretar la evolución tecnológica (o, más bien, su aplicación práctica) como el fundamento de una transformación económica radical es muy arriesgado. Considerar que las formas de consumo avanzadas que tienen lugar en internet prefiguran una evolución del conjunto de formas de consumo ( $y$, según la misma hipótesis, el modo de producción correspondiente) es un ejercicio metonímico muy arriesgado. En realidad, hay pocos indicios de que, fuera del ámbito de esos usos determinados de internet, las formas de consumo en general estén variando en el sentido de un 'empoderamiento', sea referido al consumidor, sea al prosumidor. $Y$ por lo que respecta a la esfera digital, tiende a ser cada vez con más intensidad un territorio progresivamente colonizado por el impulso a la mercantilización capitalista, o incluso directamente organizado desde principios lógicos y organizativos capitalistas (Comor, 2010; Fuchs, 2014; Pasquinelli, 2009). Señalemos como dato relevante el explosivo enriquecimiento que han experimentado compañías como Facebook (32.000 millones de euros de beneficios brutos solo en el 2017) o Google (89,000 millones de euros en el mismo periodo). Cifras chocantes si consideramos que ambas son compañías que, teóricamente, se dedican a prestar servicios gratuitos de acceso y circulación por la red, y que contradicen uno de los rasgos que, a juicio de algunos apologetas del prosumo, serían característicos de la nueva economía: la práctica ausencia del dinero en la inmensa mayoría de interacciones que los prosumidores operan en la red.

\section{¿Nueva economía o capitalismo postfordista?}

La tesis de que la actividad prosumidora está configurando o contribuyendo a configurar las bases materiales y estructurales de un nuevo modelo económico se apoya fundamentalmente en las potencialidades asociadas a la tecnología digital, como hemos visto, pero va más allá de la sola esfera digital. Por un lado, se afirma que el prosumidor disfruta de mayor autonomía en su actividad de la que dispone el consumidor clásico. No se trata solo de que tiene más libertad de elección entre lo que consume (sea porque dispone de una mayor oferta a su alcance, sea porque sus criterios de consumo se han refinado y acentuado); se trata principalmente de que la manera en la que consume es más abierta, diversa y, sobre todo, más creativa que antes. Además, esa supuesta creatividad tiene un efecto retroactivo e influye en el productor: a juicio de los defensores de la co-creación, por ejemplo, las empresas tienden a adaptar sus criterios de producción al 'feedback' que reciben de la fracción de consumidores más motivada y participativa. Pensemos, por citar un nuevo ejemplo, en el caso de la compañía de juguetes Lego, que durante un tiempo incentivó a los usuarios para que ideasen nuevos modelos de sus figuras a partir de las piezas que ya existían. Los diseños más atractivos eran apropiados por la compañía y comercializados, sin que, por lo demás, el prosumidor que los había creado recibiese ninguna retribución económica por ello. El prosumidor era aquí co-creador del 
producto, tanto respecto al diseño como respecto a la creación de valor. Para muchos, este ejemplo sería sintomático de la tendencia a que el fundamento del proceso económico se desplace desde la producción hacia el consumo.

Por lo que se refiere a la esfera digital en particular, Axel Bruns señala otro elemento distintivo de esta supuesta nueva economía: por ella ya no circula la clásica mercancía perfectamente distinguible que, por decir así, sale de la fábrica acabada (Bruns, 2007). Por el contrario, generalmente es un objeto inacabado, a medio camino entre la materia prima y lo ya producido, que fluye por las redes digitales en un continuo proceso de reelaboración y modificación. Bruns denomina a esta actividad produsage (neologismo resultado de unir production y usage), aunque por nuestra parte entendemos que las diferencias respecto a la actividad de prosumo son poco relevantes. En cualquier caso, la lógica que dominaría este produsage se basaría en la colaboración y la actividad en red. Gracias a ello los contenidos producidos/consumidos pueden proliferar por internet y ser compartidos por los usuarios sin restricciones ni jerarquías, sin órganos decisorios centralizados, y sin una planificación previa que decida dónde, cómo y qué prosumir. George Ritzer va un paso más allá y defiende que el prosumo es una forma económica radicalmente nueva. Sostiene que entre sus rasgos identificadores destaca el principio de la sobre-abundancia y la proliferación, del que ya hemos hablado; este principio regulador marcaría una diferencia radical respecto a la lógica de la producción capitalista, basada en la escasez de recursos y en la lógica de la distribución de unos medios finitos a la satisfacción de unas necesidades ilimitadas (Ritzer, 2010). En otras palabras, en la nueva economía el criterio clásico de eficiencia productiva (producir de la forma más racional posible) tendería a ser substituido por el criterio de eficiencia selectiva (elegir de la forma más racional). Ritzer señala también que en el prosumo digital el beneficio económico juega un papel secundario o nulo: supuestamente los prosumidores crean, comparten, modifican y difunden contenidos, datos y aplicaciones de forma gratuita y colaborativa, sin esperar (con frecuencia, sin desear) ser recompensados materialmente por ello.

Ahora bien, cabe preguntarse hasta qué punto todos estos rasgos rebasan los márgenes de determinados usos de la tecnología digital y se extienden por otros espacios de consumo. En otras palabras: ¿está esa hipotética lógica colaborativa y, casi se podría decir, desinteresada, influyendo en el resto de la economía? ¿O quizá tiene por el momento una extensión marginal, pero su crecimiento permite augurar que en un futuro pasará a adoptar un papel hegemónico sobre la producción típicamente capitalista? Puede ser aún pronto para juzgarlo y, en cualquier caso, la configuración que supuestamente define al prosumo lo hace muy difícil de cuantificar y, por tanto, de evaluar. Aún así, al considerar la tendencia de los últimos años parece que el movimiento es justo el inverso. La economía sigue fírmemente gobernada por la lógica capitalista, y eso vale igual para la economía digital. Es más, la tendencia a la mercantilización del mundo digital, muy visible por lo que respecta a la publicidad, pero que se materializa en muchas otras formas, parece imparable. Ante este estado de cosas, la cuestión de si estamos ante el principio de una nueva economía se abre a dos preguntas concatenadas: la primera, si la actividad prosumidora se puede caracterizar por la producción y consumo de medios de vida (es decir, de valores de uso), en sustitución de la producción de mercancías (es decir, de valores o valores de cambio). La segunda, si esa producción de medios de vida está desplazando a la producción de mercancías de forma relevante (Comor, 2010). No parece que sea el caso, como mínimo para esto último. Lo visto hasta ahora nos hace pensar que responder afirmativamente sería un ejercicio de inocencia (o de cinismo) similar al que llevó a Toffler a postular al prosumidor como la figura dominante de la futura nueva economía, treinta años atrás. 


\section{El debate en torno a la (con)fusión entre producción y consumo}

El sistema de producción capitalista se ha organizado históricamente (al menos eso nos dice la teoría) a partir de una rígida distinción entre las fases productiva, distribuidora y consumidora. Las mercancías eran creadas en las plantas de producción y montaje, literalmente fuera de la vista de los consumidores, y solo una vez acabadas eran enviadas a los circuitos de distribución y puestas al alcance de los consumidores. La teoría marxista, por su parte, afirma que en este modo de producción el valor de la mercancía solo puede crearse en la fase productiva. La fase consumidora, supuestamente, no añade valor a lo producido en la medida en que, si en ella tiene lugar algún tipo de trabajo, por sus características no es susceptible de extracción de plusvalor. Para el capitalista, por lo demás, el consumo no es más que el momento en el que su beneficio se hace material.

También la teoría económica ortodoxa ha tendido a concebir el consumo como una actividad marginal desde el punto de vista económico, en el sentido de que sería una actividad que no tendría consecuencias fuera de sí misma. La misma palabra 'consumir' se ha solido asociar a nociones negativas como desgaste, agotamiento, destrucción o finalización de un proceso. Los economistas, de hecho, han acostumbrado históricamente a concebir el consumo como un proceso pasivo, en el sentido de que no generaría nada nuevo, a diferencia de la producción, que sería un proceso creativo. En gran medida esto es consecuencia de que la economía ortodoxa solía reducir conceptualmente el proceso de consumo a la demanda (es decir, al puro acto de adquisición). La mayoría de economistas ortodoxos han tendido a coincidir aquí con los marxistas en considerar que lo relevante del consumo era que servía para 'realizar' el valor de la mercancía, para hacerlo efectivo.

Esta concepción productivista del origen del valor ha sido cuestionada al menos desde mediados de los años 80 desde el lado de la ortodoxia. Michael Porter, por ejemplo, introdujo la teoría de la cadena de valor para afirmar que debían tenerse en cuenta todas las fases por las que pasa una mercancía en el seno de una empresa (incluyendo la logística, el marketing y el servicio al cliente) para determinar el valor final del producto (Porter, 1989). Bruns de hecho parte de esta idea y la extiende al consumo al defender que, en el nuevo modelo económico del produsage el valor de la mercancía se puede incorporar a lo largo de toda la cadena producción-distribución-consumo, en la medida en que tanto en la distribución como en el consumo hay procesos activos que transforman y añaden utilidad a la mercancía (Bruns, 2007). En la misma línea, Ashlee Humphreys afirma que en el modelo productivo contemporáneo el consumo ya está plenamente integrado en la cadena de producción de valor de la mercancía (Humphreys, 2008). Otros autores en la economía ortodoxa defienden la 'productividad' del consumo y argumentan que toda actividad de consumo implica, de una forma u otra, algún tipo de trabajo, de producción, aunque sea en el sentido más elemental de la auto-reproducción (Clarke, 2003). Más aún, hay quien afirma que los consumidores tienden a actuar creativamente al utilizar los bienes que consumen, lo que con frecuencia redunda en el incremento de su valor (Xie, Bagozzi, Troye, 2008).

Todos estos planteamientos están muy alejados de la teoría del plusvalor, y por lo general parten del rechazo a distinguir entre valor de uso y valor de cambio. Pero en nuestro contexto tienen un cierto interés en la medida que abren la discusión sobre el problema de la productividad del consumo: es decir, la cuestión de si la actividad de consumo puede ser, en sí misma, productiva. Una cuestión fundamental porque, de ser así, la conclusión lógica es que el consumo es susceptible, al menos hipotéticamente, de generar algún tipo de valor. Para ilustrar 
esta posibilidad, consideremos el caso de las marcas comerciales. Es bien conocido que el éxito de muchas empresas, por ejemplo en el caso de Nike, se basa en la fama y el reconocimiento que adquiere su marca (materializada en un logo) entre los usuarios (Klein, 2011). Ahora bien, esa fama no es simplemente el resultado de una acertada política de publicidad, sino que también se asienta en gran medida en la visibilidad que consiguen los productos de esa empresa por el simple hecho de ser usados de forma pública. La teoría del prosumo afirmaría que el mero acto de llevar unas Nike por la calle contribuye, por sí mismo, a valorizar la marca y, por su mediación, la del conjunto de mercancías que se comercializan bajo ese logo. Es decir que la actividad de calzar públicamente (consumir) unas zapatillas Nike les estaría añadiendo valor.

Consideremos un ejemplo más: la famosa estantería Billy de la empresa lkea. Cuando un usuario compra, transporta y monta esta estantería, supuestamente lleva a cabo una evidente actividad prosumidora: tiene que ejecutar una cantidad de trabajo necesario para poder dejarla en condiciones de uso. Muchos defienden que esa actividad es libre, creativa, e incluso divertida, lo que dificulta que pueda ser considerada como trabajo. Sea esto así o no, lo que cabe señalar es que el prosumidor que transporta y monta la estantería, en realidad, está sustituyendo con su propio trabajo el trabajo de un asalariado que, de otra forma, Ikea hubiese debido contratar. En realidad la propia Ikea se enorgullece de que su política de precios bajos se basa en trasladar una parte de los costos de producción y distribución (el traslado y el montaje) al consumidor. El hipotético prosumo, aquí, sigue sometido a la lógica capitalista; incluso se podría decir que se pone a su servicio, en el sentido que George Ritzer ya había formulado hace años en su famosa tesis de la macdonaldización de la sociedad (Ritzer, 1996).

En definitiva, parece que hay suficientes elementos, tanto teóricos como materiales, para postular que, efectivamente, en el consumo puede hallarse una dimensión, por así decir, 'productiva' o 'creadora'. La cuestión pasa por definir qué tipo de 'valor' se estaría generando desde esa dimensión. Volveremos a esto más adelante.

\section{¿El prosumo como promesa de liberación?}

Un tercer gran campo de discusión sobre la naturaleza del prosumo se estructura alrededor de la cuestión de la autonomía de que gozaría el prosumidor en el plano económico. Quienes defienden la teórica capacidad del prosumo para 'liberar', 'proporcionar autonomía' o 'empoderar' al consumidor no hacen más que retomar, de una u otra manera, una vieja tesis postmoderna de los años 80. Esta tesis fue popularizada entre otros por Gilles Lipovetsky (Lipovetsky, 1983) y argumentaba que la creciente importancia del consumo en las sociedades postfordistas se materializaba, en la práctica, en una actitud cada vez más hedonista y en un creciente culto a la personalidad individual. El consumo, según esta tesis, proporcionaría a los individuos un espacio para la libertad y la expresión subjetiva, un campo en el que poder dar rienda suelta a sus deseos, gustos y motivaciones, al mismo tiempo que proyectar de forma muy efectiva su imagen ante los demás. Pues bien, en su versión contemporánea esta tesis abona la idea de que el prosumo es la profundización de aquella tendencia, en la medida que añade a aquel consumo 'liberador' postmoderno de los 80 y los 90 una dimensión productiva y creativa más contemporánea. El prosumidor es presentado así como un sujeto activo, creador, que por diferentes mecanismos imprime sus gustos e intereses sobre los objetos consumidos, bien sea modificándolos él mismo, bien presionando sobre las compañías que los producen para que los adapten a tales gustos. 
Para entender en toda su profundidad la defensa de la dimensión 'empoderadora' del prosumo es necesario hacer una breve mención a la teoría de la alienación. La alienación es causada por una separación del sujeto productivo (el trabajador) respecto de cuatro elementos:

a) Del sistema productivo (el trabajador no es propietario de los medios de producción que utiliza para trabajar).

b) De su propia actividad productiva (en el sentido que no es libre para trabajar como quiera, sino que debe someterse a las órdenes de otros y/o a una lógica productiva que se le impone).

c) Del resultado de su actividad (unas mercancías que, aunque producidas por él, no le pertenecen).

d) De los otros trabajadores (bien sea por la competencia en el mercado laboral, bien porque, a medida que el trabajo se hace más mecánico, el trabajador se convierte en una pieza más de un engranaje automatizado e impersonal).

Desde el discurso que defiende el prosumo se sostiene que la actividad del prosumo supone una superación de estos cuatro niveles de separación o 'alienación'. El prosumidor a menudo posee o controla sus medios de producción (desde los ordenadores personales y otros dispositivos digitales hasta la simple caja de herramientas para hacer 'chapuzas' en el hogar). También tiene una gran libertad para decidir sobre cómo, qué y cuándo 'prosumir'. Supuestamente es propietario de aquello que prosume (en el sentido de que, una vez lo adquiere, puede disponer de ello como desee). Y por último, y sobre todo respecto del prosumo digital, con frecuencia interactúa con los otros usuarios intercambiando y colaborando, produciendo y consumiendo de forma comunitaria.

Ahora bien, cabe cuestionarse en qué medida estos factores responden a una auténtica capacidad liberadora de la actividad prosumidora respecto a los condicionamientos del sistema capitalista. Para empezar, el supuesto control de los medios de producción (o, si se quiere, de los medios de prosumo) que tendría el prosumidor se da a niveles muy elementales, ya que las grandes compañías siguen poseyendo la tecnología, los instrumentos y el control sobre los grandes medios económicos. También hay que señalar que, en realidad, son muy pocos los usuarios que tienen auténtica autonomía para consumir como desean, particularmente en la esfera digital. Recurramos de nuevo a un ejemplo: esta vez el de un perfil de Facebook. Se trata de hecho de un diseño digital muy rígido, con una estructura que ante el usuario aparece bajo la forma de una interfaz sobre la que no tiene ninguna opción de transformación o manipulación. El usuario de Facebook está obligado a utilizarlo bajo las condiciones y el formato que impone la propia compañía, y la supuesta libertad que supuestamente debería caracterizar su uso es en realidad una ilusión que oculta un sometimiento real a los intereses económicos de la empresa.

Acabemos con un argumento aportado por Edward Comor para rechazar el supuesto empoderamiento que acompaña al prosumo digital: es bien sabido que, con frecuencia, la actividad que realiza el prosumidor en su navegación por la red es cooptado por diversas empresas sin que él lo sepa, y por supuesto sin que sea remunerado. El desarrollo de sistemas de tratamiento de la información del Big Data con fines publicitarios es un caso bien conocido, pero se trata solo de la punta del iceberg del aprovechamiento empresarial de la información generada por los propios usuarios en internet. En este sentido, el resultado de la actividad prosumidora sería todo lo contrario de una liberación: se estaría produciendo en realidad una explotación encubierta de esa actividad (Comor, 2010). Ahora bien, sin negar que esta forma de explotación es real, cabe dudar si en estos casos podemos hablar de prosumo, o estamos tratando con otra cuestión. Lo que nos lleva al siguiente punto en nuestra argumentación. 


\section{La crítica del concepto de prosumo}

Una vez delimitado el campo de discusión en el que se sitúa el concepto de prosumo, estamos en situación de revisar críticamente su contenido. Puesto que el nombre no hace a la cosa, de lo que se trata es de determinar si el prosumo describe un fenómeno social y económico nuevo, o si por el contrario es simplemente un artificio teórico mediante el que se tratan de legitimar prácticas de explotación del trabajo no asalariado que, por lo demás, son tan antiguas como el mismo capitalismo.

A raíz de lo anterior, hay que destacar una aparente obviedad: si existe algo tal que el prosumo, este consistirá en una actividad que no sólo debe realizar el supuesto prosumidor, sino que además la ha de llevar a cabo de forma consciente, deliberada. Así, hay que diferenciar el prosumo en sí de otras actividades que, aunque tengan lugar en la esfera del consumo y puedan considerarse productivas, son realizadas por terceros sobre la actividad de los consumidores. El consumo de publicidad, digital o analógica, así como a la gestión de los datos de navegación que generan los usuarios de internet en algoritmos como PageRank, son ejemplos obvios. Por un lado, es innegable que, en estos casos, la actividad del usuario con frecuencia o bien tiene efectos productivos, o bien afecta a la producción. Muchas empresas utilizan datos proporcionados por el Big Data para adaptar sus estrategias a las fluctuaciones de las modas y gustos imperantes en tiempo prácticamente real. Pero esto no basta para englobar todos estos casos dentro del prosumo, puesto que quienes llevan a cabo son las empresas: el consumidor es aquí un 'paciente' de la actividad, antes que un 'agente'. El simple acto de navegar por internet, sin tener en consideración en qué actividad concreta se materializa, no puede ser catalogado como prosumo sin más. Los datos que genera esa navegación pueden ser procesados mediante algoritmos como PageRank para ser comercializados, por ejemplo para empresas de publicidad. Pero en este sentido la actividad del usuario es involuntaria, y se puede concebir algo así como la materia prima sobre la que se aplica el trabajo de terceros. Parece así que, para que se pueda hablar de prosumo, es necesario que la actividad del prosumidor sea consciente, es decir, que él mismo sea el responsable de la 'productividad' de su consumo.

Hecha esta aclaración, vamos ahora a tratar de perfilar qué se debería entender como prosumo. Puesto que su esfera es el consumo, forma parte de una realidad proteica y multifacética, difícilmente sintetizable en el plano teórico. Para aclarar un poco más el campo del prosumo, vamos a distinguir entre dos formas principales de prosumir: el prosumo de primera generación o, por decir así, analógico, y el prosumo de segunda generación o digital, basándonos libremente en un criterio de clasificación que estableció Ritzer (Ritzer, 2010, p. 18).

Respecto al prosumo analógico, estaríamos hablando de actividades tan clásicas como el bricolaje, o tan modernas como montar un mueble de Ikea; pero también algunas no tan obvias a primera vista como el autoservicio en una gasolina low-cost, comer en un McDonald's, o pasar los productos de la propia compra por el lector de barras en un supermercado. Todas estas prácticas comparten el hecho de que hay una parte de trabajo que realiza el consumidor y que, o bien tradicionalmente formaban parte de las fases productiva o distributiva y son trasladadas a la fase de consumo, o bien añaden algún tipo de valor al producto consumido. Ahora bien, en cierta manera este tipo de trabajo ha existido siempre: recordemos, sin ir más lejos, que durante el siglo XIX la industria textil no comercializaba prendas ya confeccionadas, sino que producía la tela base que posteriormente los consumidores (de hecho, las consumidoras: la mayoría mujeres de clase trabajadora) transformaban en prendas de vestir en sus propios hogares. Por 
tanto, podría argüirse que el consumo ha contenido desde siempre una dimensión prosumidora $y$, en consecuencia, no tendría sentido recurrir a una nueva palabra para describir algo ya existente. A menos (y aquí está el principal punto de discusión, a nuestro juicio) que la productividad del consumo no se limite a añadir valor de uso, sino que también añada valor (valor de cambio) (Humphreys, 2008, p. 8). En tal caso, considerar el prosumo desde una perspectiva crítica crítica sería más que pertinente.

El supuesto prosumo de segunda generación o 'digital', como hemos ido viendo, sería una forma particular de prosumo que nacería con las tecnologías digitales, muy particularmente con las capacidades asociadas a la web 2.0, y que tendría rasgos específicos. Ya hemos mencionado que, gracias a esas tecnologías, los usuarios no solo están interconectados, sino que pueden producir, difundir y compartir sus propios contenidos. En este sentido, la concepción de plataformas como Facebook, Twitter, Instagram o Youtube no es casual: han sido pensadas y diseñadas para incentivar un consumo fundamentalmente productivo de internet. Reclaman de la mayoría de usuarios una implicación intensa, su participación en la generación y manipulación de contenidos, así como la interacción con otros usuarios en una espiral comunicativa sin fin. Proporcionan, por tanto, el espacio idóneo para la actividad prosumidora. Por otro lado, y a diferencia del prosumo 'analógico', aquí nos encontraríamos ante un consumo que se podría definir como inmaterial, en el sentido de que no se objetiva en una mercancía sólida: por lo general se trata de información, de datos digitalizados que circulan por la web, o bien de servicios asociados al acceso y gestión de esos datos. El prosumo de segunda generación, así, se despliega en un terreno menos palpable y más difuso que el que caracteriza al prosumo de primera generación, lo que complica su análisis.

Llegados a este punto, quizá sería conveniente abordar una definición del prosumo, aunque solo sea tentativa, para poder avanzar en la discusión. Xie, Bagozzi y Troye lo han descrito formalmente como aquellas "actividades de creación de valor realizadas por el consumidor que resultan en la producción de productos (sic) que acaba consumiendo y que se convierten en sus experiencias de consumo"3 (Xie, Bagozzi, Troye, 2008, p. 110). Aunque imprecisa a nuestro juicio, esta definición nos es útil en la medida que menciona algunas de las características fundamentales que deberían informar el prosumo:

- Se trataría de (a) una actividad productiva que resulta en (b) la creación de valor.

- $\quad$ Es llevada a cabo por el consumidor.

- $\quad$ Tiene lugar en la fase de consumo.

Ahora bien, por lo visto hasta ahora, es claro que estas características son necesarias pero no suficientes para admitir la existencia de un prosumo. En primer lugar, la afirmación de que se trata de una "actividad de creación de valor" es imprecisa: como ya hemos insistido, desde nuestro punto de vista la noción de valor que se esgrime aquí no tiene ningún contenido específico. El prosumo requiere de la producción de valor en el sentido de valor de cambio, diferenciado del valor de uso. $Y$ esto, por tanto, nos conduce a la necesidad de que se produzca la extracción de algún tipo de plusvalor. En segundo lugar, es cierto que se trata de una actividad realizada por el consumidor y durante la fase de consumo; pero esta afirmación, sin más, no deja de ser una tautología. Lo realmente decisivo, y lo que en este sentido diferenciaría al prosumo de un consumo más o menos productivo, es que la creación de valor

3 Traducción propia. El original inglés es este: "value creation activities undertaken by the consumer that result in the production of products they eventually consume and that become their consumption experiencies". 
que resulta de la actividad prosumidora es llevada a cabo de forma deliberada, consciente, por el prosumidor: ni es creada de forma accidental, ni realizada por terceros. Maticemos este punto: aunque desde la perspectiva del prosumidor es probable que considere lo que esté generando como simple valor de uso, lo fundamental para el prosumo es que está produciendo valor de cambio. Dicho de otra forma, mientras su conciencia está orientada al valor de uso, sus actos lo están (al menos, parcialmente) hacia el valor.

Esto nos lleva a una tercera consideración. En el sistema de producción capitalista, del que el consumo forma parte, la producción de valor va asociada necesariamente a la existencia de plusvalor. Y, por su parte, el plusvalor se fundamenta en la explotación de trabajo asalariado. Esto nos coloca en una paradoja, pues si hay algo que parecería obvio respecto al prosumo es que bajo ninguna circunstancia debería consistir en trabajo asalariado. ¿Cómo puede generarse valor en el prosumo, si por definición es una actividad no remunerada, de hecho realizada fuera de la esfera productiva formal? En la medida en la que el prosumidor reciba algún tipo de contraprestación monetaria por su actividad, ésta dejará de ser prosumo y pasará a ser, simple y llanamente, trabajo asalariado.

Si se piensa bien, la relación entre el prosumo y el trabajo asalariado parece ser más bien la contraria: en el prosumo se da una forma de actividad productiva que sustituye a un trabajo que, estrictamente, debería ser remunerado. Así, el proceso de montar en casa un mueble de lkea sería una actividad de prosumo en la medida en que el usuario no solo estaría haciendo útiles (creando valor de uso) las piezas separadas del mueble, sino que además estaría sustituyendo con su propio trabajo el trabajo que, de otra forma, debería haber realizado un trabajador de la empresa. Ahora bien, ¿se genera plusvalor de esta manera? No parece ser el caso. La actividad prosumidora es necesaria para que ese mueble tenga un valor de uso, pero en su precio como mercancía no está incluido el coste del trabajo que se hubiese necesitado para montarlo en la fase productiva. De manera que ese es un trabajo en absoluto remunerado, del que no es posible extraer plusvalor.

Puede pensarse, entonces, que el prosumo sería cualquier actividad de consumo que incorporase elementos de las fases productiva y/o distributiva del proceso de circulación del capital. Esos elementos, si se llevasen a cabo en tales fases, se tratarían formalmente como trabajo remunerado (susceptible de generar plusvalor), pero al ser realizados en la fase de consumo, dejan de serlo. Según esto, el prosumo sería una combinación particular de consumo y producción, o más precisamente, una combinación de consumo "formal" y trabajo "informal". Un trabajo que, en la medida en que tiene lugar fuera de la esfera tradicional de la producción, ni es reconocido como tal, ni es retribuido.

\section{Conclusión}

Hemos visto que, en su versión más extrema, la hipótesis del prosumo defiende que se trata de una praxis económica inédita que habría de convertirse en el fundamento de un (posible) nuevo modelo económico. Existen sólidos argumentos para dudar tanto de las supuestas bondades que acompañarían a esta praxis, como de su capacidad para impulsar ese nuevo modelo. Más allá de este debate (de por sí interesante), entendemos que la cuestión principal en torno al prosumo pasa por determinar la naturaleza de la dimensión productiva del consumo o, si se prefiere, del trabajo de consumo, y su explotación en el capitalismo contemporáneo. La existencia de ese trabajo de consumo está fuera de toda duda: lo ha acompañado desde siempre. Pero la idea del prosumo pretende ir un paso más allá: a diferencia de la actividad 
simple del consumo, que no se trasciende a sí misma, se afirma que la actividad prosumidora rebasaría la esfera del consumo y se extendería a la esfera de la producción, particularmente respecto de la creación de valor.

En la perspectiva adoptada aquí esto sólo puede ser concebible en dos formas. Una posibilidad sería que la actividad de prosumo incorporase una parte de trabajo remunerado. Como se ha señalado, en la medida en la que el trabajo remunerado y el consumo son mutuamente excluyentes, esto es una contradicción lógica, de manera que esta posibilidad puede ser descartada (incluso aunque el prosumo se basase en la producción individual de mercancías o servicios, pues en este caso estaríamos ante trabajo remunerado en régimen de autoexplotación). La segunda posibilidad es que la productividad que caracteriza al prosumo sea explotada por las empresas de forma directa, sin una contraprestación económica. Es decir, que en el prosumo haya trabajo, pero sea no remunerado. Esta posibilidad parece más adecuada a buena parte de las prácticas que se suelen catalogar como prosumo, de las que hemos ofrecido una amplia selección de ejemplos. Ahora bien, en la medida en la que el trabajo que acompaña al prosumo es voluntario, pero no remunerado, no podemos hablar de explotación en un sentido estrictamente capitalista. Aunque existan empresas que extraigan un beneficio de ahí, de lo que se trata es de una explotación simple y directa, no específicamente capitalista, de la capacidad del trabajo de crear valor.

Podemos concluir afirmando que la actividad que se suele definir bajo el término prosumo no tiene identidad específica propia para justificar el uso de la palabra. En la medida en la que la productividad del consumo se canalice hacia el incremento del valor de uso de un objeto consumido por parte del consumidor, estaremos ante un rasgo que ha acompañado al consumo desde sus orígenes, y que de hecho es una parte fundamental de la reproducción del sujeto consumidor. Desde cocinar un plato hasta montar un videoclip editando imágenes sobre la base de una canción, existe una gama infinita de formas en las que el consumidor personaliza o simplemente hace más útil aquello que consume. Todas ellas son o pueden llegar a ser productivas, pero no es necesario acudir a un concepto nuevo para describirlas. Si, por el contrario, la productividad del consumo se encamina a la creación de valor en sentido estricto, o bien estamos ante trabajo asalariado ( $\mathrm{y}$ en este caso no cabe hablar ni de prosumo, ni de consumo), o bien ante una forma de explotación del trabajo indirecta e informal (informal en el sentido de que no es reconocida explícita e institucionalmente). En última instancia, este último caso es el realmente relevante. Nos lleva a constatar que la hipótesis del prosumo aparece, finalmente, como una gran hipóstasis. Como la piel del cordero bajo la que se disfraza el lobo, tiende a ser utilizada para ocultar, tras una formulación promisoria, la explotación directa del trabajo ajeno. Una forma de explotación que, aunque formalmente ajena a la "normatividad" de la lógica y el modo capitalista, es aprovechada por múltiples empresas para aumentar sus beneficios. 


\section{Referencias}

Bruns, A. (2008). Blogs, Wikipedia, Second Life, and Beyond: From Production to Produsage. New York: Peter Lang.

Burrows, R. \& Beer, D. (2010). Consumption, Prosumption and Participatory Web Cultures. An Introduction. Journal of Consumer Culture, 10 (1), 3-12.

Comor, E. (2010). Digital Prosumption and Alienation. Ephemera, 10 (3), 439-454.

Fuchs, C. (2011). Web 2.0, Prosumption and Surveillance. Surveillance \& Society, 8 (3), 288309.

Fuchs, C. (2014). Digital Prosumption Labour on Social Media in the Context of the Capitalist Regime of Time. Time \& Society, 23 (1), 97-123.

Humphreys, A. \& Grayson, K. (2008). The Intersecting Roles of Consumer and Producer: A Critical Perspective on Co-production, Co-creation and Prosumption. Sociology Compass, 2.

Klein, N. (2011). No Logo: el poder de las marcas. Barcelona, Paidós.

Pasquinelli, M. (2009). Google's PageRank Algorithm: A Diagram of the Cognitive Capitalism and the Rentier of the Common Intellect. En Konrad Becker and Felix Stalder (Eds.), Deep Search: The Politics of Search Beyond Google. London: Transaction Publisher.

Porter, M. (1989). Ventaja competitiva. Creación y desarrollo de un desempeño superior. México, CECSA.

Prahalad, C. K. \& Ramaswamy, V. (2000). Co-opting Customer Competence. Harvard Business Review.

Ramirez, R. (1999). Value Co-production: Intellectual Origins and Implication for Practice and Research. Strategic Management Journal, 20, 49-65.

Ritzer, G. (1996). La Macdonaldización de la sociedad. Barcelona: Ariel.

Ritzer, G. (2005). Enchanting a disenchanted world: Revolutionizing the means of consumption. London: Pine Forge Press.

Ritzer, G. (2010). Production, Consumption, Prosumption. The nature of capitalism in the age of the 'digital' prosumer. Journal of Consumer Culture, 10 (1), 13-36.

Ritzer, G, Dean, P. \& Jurgenson, N. (2012). The coming of age of the prosumer. American Behavioral Scientist, 56 (4), 379-398.

Ritzer, G. (2015). Automating Prosumption: The decline of the prosumption and the rise of the prosumer machines. Journal of Consumer Culture, 15 (3), 407-424.

Tapscott, D. (1998). Growing Up Digital: The Rise of the Net Generation. New York: McGraw-Hill Companies.

Terranova, T. (2000). Free Labor: Producing Culture for the Digital Economy. Social Text, 18 (2).

Toffler, A. (1980). La tercera ola. Barcelona: Plaza y Janés.

Zwick, D. \& Bonsu, S. \& Darmody, A. (2008). Putting Consumers to Work. Co-creation and marketing govern-mentality. Journal of Consumer Culture, 8 (2), 163-196. 
